\title{
Exploring the factors that affect the intention to use collaborative technologies: The differing perspectives of sequential/global learners
}

\author{
Yong-Ming Huang \\ Chia Nan University of Pharmacy and Science, Taiwan
}

\begin{abstract}
The use of collaborative technologies in learning has received considerable attention in recent years, but few studies to date have examined the factors that affect sequential and global learners' intention to use such technologies. Previous studies have shown that the learners of different learning styles have different needs for educational technologies. Accordingly, understanding the factors that affect the different types of learners' intention to use collaborative technologies is an important issue. To this end, we add two external variables, facilitating conditions and social influence, to the technology acceptance model and then testing a number of hypotheses. Our results show that most of the hypotheses are supported, and further reveal that (1) attitude towards using is the most important determinant of students' intention to use a collaborative technology, followed by social influence and facilitating conditions; (2) sequential learners are more concerned about perceived usefulness; (3) global learners are more concerned about perceived ease of use.
\end{abstract}

\section{Introduction}

Collaborative technologies have particular value in education, because they can be used to help students achieve collaborative learning (Coll, Rochera, \& Gispert, 2014; Huang, Wang, Guo, Shih, \& Chen, 2013; Park \& Seo, 2013; Sung \& Hwang, 2013). Collaborative technologies refer to information and communication technologies that enable individuals to collaborate in a common task (Lee, Cheung, Tsui, \& Kwok, 2007), while collaborative learning derives from constructivist theory, which believes that knowledge should be developed through the discussions and interactions between individuals (Geary, 1995; Schunk, 1996); that is to say, knowledge should not be simply transmitted from teacher to students, but rather the students actively construct the knowledge through collaboration (Harel \& Papert, 1991; Palincsar, 1998). Accordingly, collaborative technologies provide students with a context in which they can discuss, argue, and negotiate their ideas, so as to collaboratively construct their own knowledge.

Several investigations have already been carried out to apply collaborative technologies to learning. An early work in this area, Chiu, Huang, and Chang (2000), developed a network-supported collaborative concept mapping tool to assist students in jointly constructing their concept maps. Their results show that learning performance was significantly correlated to the level of group interaction and the amount of complex cooperative interaction. Similarly, McCarthy, Bligh, Jennings, and Tangney (2005) implemented a network-supported collaborative music composition tool that provides a shared virtual space in which two or more students can jointly create and manipulate a piece of music. Their findings show that the tool provided students with positive feelings of interdependence from each other, and that they enjoyed providing help with creating the piece of music, as well as exchanging resources, information, and ideas. Later, Wang (2009) designed a collaborative learning environment to facilitate group collaboration among students. Specifically, the students were asked to work in pairs to design a learning package, with material that could take any form, such as PowerPoint files or web pages. An online storage tool was used to help the students collaboratively manage the materials, and using this they could create folders, upload and download files, and then invite others to view these and make comments on them. In addition, each student was asked to make a progress report informing their partner what changes they had made or what tasks they had completed, why they had taken a specific action, and what further actions still needed to be carried out. The results show that these progress reports were useful for coordinating and monitoring the learning process. However, Wang (2010) noted that while collaboration is essential in today's information age, monitoring a collaborative learning process and assessing individual contributions can be very difficult. The study recommended using an online shared workspace to deal with this issue, because it is capable of automatically recording certain data, which the teacher can then use to track the collaborative learning process and assess the contributions of individual students. In addition, Wang also stated that writing progress reports can help students to reflect on what they have done, and further assist the teacher 
in monitoring the collaborative process and the work of each individual. Recently, Sung and Hwang (2013) developed a collaborative game-based learning environment, in which a grid-based mind tool was integrated in order to help the students organise their knowledge in a collaborative manner. The tool was developed using Google Sites, which is a structured collaborative system-development tool offered by Google, and it enabled the students to organise both what they had learned from the game and their discussions with peers. Their results show that the proposed collaborative learning environment was useful in improving both the learning attitudes and learning motivation of the students, as well as raising their learning achievement and self-efficacy.

Despite the efforts of these earlier works, few studies have explored the factors that affect students' intention to use collaborative technologies from the perspective of learning styles. Understanding the factors that affect students' intention to use educational technologies is a vital issue (Escobar-Rodriguez \& Monge-Lozano, 2012), because they can be used as important indicators to successfully develop technologies (Chatzoglou, Sarigiannidis, Vraimaki, \& Diamantidis, 2009; Davis, 1989; Davis, Bagozzi, \& Warshaw, 1989; Huang, Huang, Huang, \& Lin, 2012b). To this end, Liaw, Chen, and Huang (2008) examined the effects of system satisfaction, system functions and so forth on the adoption of web-based collaborative learning systems. More recently, Cheung and Vogel (2013) used an extension of the technology acceptance model to explore the factors that affect students' intention to use collaborative technologies. However, these studies only focused on the factors that affect students' intention to use, and did not explore those that affect the intention to use based on different learning styles. Learning styles are viewed as an important factor in the influencing of learning outcomes (Jeffrey, 2009). Previous studies have shown that when an educational system is able to fit the need of students according to their learning styles, then the learning performance of students will be improved significantly via that system (Hwang, Sung, Hung, \& Huang, 2013; Hwang, Sung, Hung, Huang, \& Tsai, 2012). This means that students of different learning styles have different needs for educational technologies. Accordingly, learning styles need to be considered when examining students' intention to use collaborative technologies.

In this study, our goal is to extend the technology acceptance model (TAM) (Davis, 1989; Davis et al., 1989) to develop a research model to explore the factors that affect students' intention to use collaborative technologies. Specifically, we apply a well-known synchronous collaboration technology, called Prezi, to a university course in conjunction with a questionnaire in order to examine whether there are any differences in students' perceptions of collaborative technology based on their learning styles. Finally, a series of analyses are undertaken to examine the model, on which our conclusions are based. Accordingly, the contribution of this study includes the validation of the TAM for explaining or predicting students' intention to use collaborative technologies based on their learning styles. We thus analyse a number of other factors that may affect the intention to use collaborative technologies, as well as the acceptance of such technologies. Based on the results of this work, we also present some important practical implications for the acceptance and usage of these technologies in education.

\section{Related studies}

\section{Learning styles}

Learning styles refer to "characteristic cognitive, affective, and psychological behaviors that serve as relatively stable indicators of how learners perceive, interact with, and respond to the learning environment” (Keefe, 1979, p. 4). Many researchers have stated that learning styles are an important factor in students' learning, and that a better understanding of them is useful for promoting learning effectiveness (Graf, Kinshuk, \& Liu, 2009; Huang, Lin, \& Huang, 2012; Hwang et al., 2012; Hwang et al., 2013; Jeffrey, 2009). Many measurement instruments have thus been developed to examine learning styles and to assess the learning preferences of students (Felder \& Silverman, 1988; Felder \& Soloman, 1997; Kolb, 1984). Perhaps the most well-known and often used learning style model, especially in the field of e-learning, is the index of learning styles (ILS), developed by Felder and Soloman (1997) (Hwang et al., 2012; Hwang et al., 2013). The ILS is based on the Felder-Silverman learning style model proposed by Felder and Silverman (1988), and is more comprehensive than other such models, including the learning style inventory (Kolb, 1984). The ILS categorises the learning styles of students using four dimensions: sensory/intuitive, visual/verbal, active/reflective, and sequential/global. The distinction between sensory/intuitive styles is based on the way of perceiving things, in which sensory students prove to be more concrete thinkers who prefer to learn practical things, and are more oriented towards facts. In 
contrast, intuitive students are more abstract thinkers who prefer to learn innovative things, and are more oriented towards theories (Filippidis \& Tsoukalas, 2009; Graf et al., 2009). The distinction between visual/verbal styles is based on how the learning material is presented, where visual students prefer pictures, diagrams and flow charts, while verbal students prefer written and spoken explanations (Filippidis \& Tsoukalas, 2009; Graf et al., 2009). The distinction between active/reflective styles is based on the way of processing things, in which active students prefer to try things out and work together, while reflective students prefer to think about things and work alone (Filippidis \& Tsoukalas, 2009; Graf et al., 2009). The distinction between sequential/global styles is based on the way of understanding things, whereby sequential students prefer linear thinking processes and learning in small incremental steps, while global students prefer holistic thinking processes and learning in large leaps (Filippidis \& Tsoukalas, 2009; Graf et al., 2009).

The sequential and global styles have received considerable attention in recent years, due to the increasing importance of e-learning (Filippidis \& Tsoukalas, 2009; Hwang et al., 2012; Hwang et al., 2013; Jeffrey, 2009). This is because e-learning environments offer a non-linear context that enables students to freely select their own learning paths. While these multiple pathways may provide greater flexibility for learning, they also impose greater skill demands on users, especially for sequential learners (Jeffrey, 2009). This is because sequential learners prefer to learn through structured, linear pathways, while global learners tend to learn in large leaps, and prefer to use a holistic thinking process. That is to say, sequential and global learners use different thinking processes in their learning, and thus the same elearning context is unlikely to meet the needs of both groups (Hwang et al., 2012; Hwang et al., 2013; Jeffrey, 2009). Accordingly, understanding how sequential and global learners see instructional software is a vital issue, as this can help software designers to develop more effective technologies, so that students can learn efficiently and effectively.

\section{The TAM}

The TAM has been widely used in studies of information technologies (Chatzoglou et al., 2009; Huang et al., 2012b), and was first developed by Davis and his colleagues (Davis, 1989; Davis et al., 1989) to explore users' perspectives on the acceptance of technologies. Davis et al. proposed four constructs, namely perceived ease of use, perceived usefulness, attitude towards using, and behavioural intention, with which to develop the model. Perceived ease of use means that individuals believe that the technology is easy to use, while perceived usefulness means that individuals believe that the technology is useful for improving their job performance (Davis, 1989). Attitude towards using refers to individuals' feeling of favorableness or unfavorableness about the technology (Fishbein \& Azjen, 1975), while behavioural intention means that individuals will engage in a specified behaviour (Chatzoglou et al., 2009). In the studies of Davis et al. (1989), the hypotheses are that (a) perceived ease of use has a positive and significant effect on perceived usefulness and attitude towards using; (b) perceived usefulness has a positive and significant effect on attitude towards using and behavioural intention; and (c) attitude towards using has a positive and significant effect on behavioural intention (Davis, 1989; Davis et al., 1989). In addition to these hypotheses, Davis et al. (1989) also suggested that some external variables (e.g., facilitating conditions and social influence) may have both direct and indirect effects on perceived ease of use, perceived usefulness and behavioural intention.

As a result of the successful development of the TAM, many educational researchers have applied the model to examine various educational technologies. For example, Chatzoglou et al. (2009) extended the TAM using other factors, such as enjoyment, self-efficacy and computer anxiety, to examine employees' intention to use a web-based training system. Their results showed that enjoyment, perceived usefulness and perceived ease of use had a direct effect on employees' intention to use the system. EscobarRodriguez and Monge-Lozano (2012) used the TAM to analyse the use of the Moodle platform by business administration students to find out how to increase its use. Their results show that perceived usefulness among professors, perceived compatibility with student tasks, and the provision of training, could all help to increase adoption of the system. Similarly, Huang et al. (2012) extended the TAM by adding system and material characteristics to explore the acceptance of a ubiquitous English vocabulary learning system. Their findings showed that both the system and material characteristics of the system positively and significantly influenced the perspectives of students on the system. Cheung and Vogel (2013) applied an enhanced TAM to examine the factors that influence the acceptance of Google applications for collaborative learning. Their findings show that subjective norms, which are the opinions 
of important others, had significant effects on the students' intentions to use the applications.

While the TAM is shown to be widely used as a tool with which to examine students' intention to use technologies, to date there have been no studies exploring the factors that affect students' intention to use collaborative technologies by considering the perspectives of sequential and global learners. To make up for this deficiency, the ILS is used in this work to explore the factors that affect the intention to use collaborative technologies Details of the research design are presented in the next section.

\section{Research design}

\section{Research}

Our investigation was structured around the following research questions:

(1) What are the students' perspectives on the collaborative technology?

(2) Are the perspectives of sequential students on the collaborative technology similar to those of global students?

\section{Research model and hypotheses}

Figure 1 shows the research model, which is based on the TAM. Facilitating conditions and social influence are used as additional factors to examine their effects on students' intention to use the collaborative technology. Facilitating conditions are the services offered by an organisation to encourage users to adopt a technology (Teo, 2009; Terzis \& Economides, 2011). Social influence means that individuals' thoughts, feelings, attitudes, or behaviours are influenced by their interactions with others (Teo, 2009; Venkatesh \& Davis, 2000; Venkatesh, Morris, Davis, \& Davis, 2003). In this work, the Prezi service is used to assist students in constructing knowledge through interactions with others. This service is a well-known synchronous collaboration technology, and is an innovative service that requires users to have certain skills, such as the configuring of synchronous collaboration, to enable them to work together. In addition, the interface of Prezi is in English, and thus non-English speakers need to spend more time and effort to learn how to use the system. Accordingly, both facilitating conditions and social influence are integrated into the research model, which consists of eight hypotheses, and which are described in detail below.

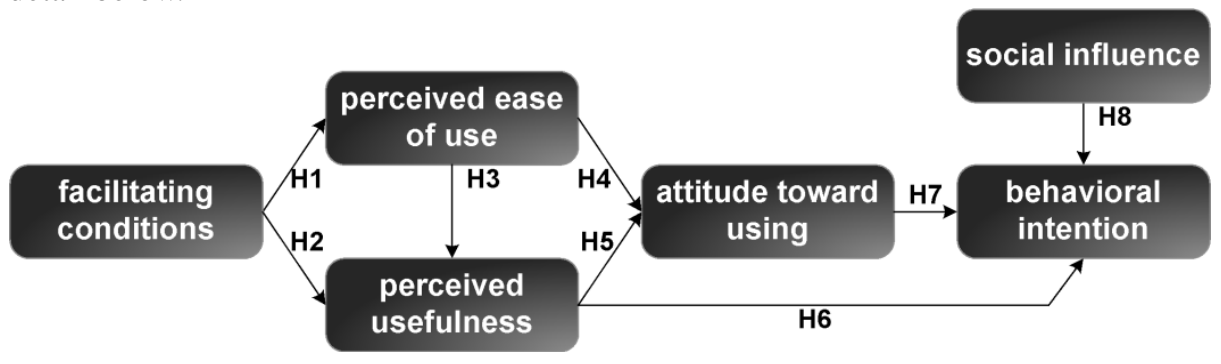

Figure 1. Research model

Facilitating conditions are factors in the environment that facilitate using a technology to perform a specific task (Teo, 2009; Terzis \& Economides, 2011). Specifically, facilitating conditions include resource factors (e.g., time for training) or technology factors (e.g., system compatibility) (Lu, Liu, Yu, \& Wang, 2008). Facilitating conditions are an important indicator for the adoption of a technology, because when users do not have sufficient time for training, or when they encounter significant difficulties with regard to system compatibility, they will demonstrate less intention to use the technology. Several studies have shown that facilitating conditions are positively related to perceived ease of use and perceived usefulness (Karaali, Gumussoy, \& Calisir, 2011; Rouibah, Hamdy, \& Al-Enezi, 2009). For example, Karaali et al. (2011) found that the perceived ease of use of a system is positively affected by the guidance and specialised instructions of the system. Similarly, Rouibah et al. (2009) demonstrated that both the perceived ease of use and the perceived usefulness of a system are positively affected by facilitating conditions, such as the availability of training and resources. In this study, the facilitating 
conditions include the guidance and instructions needed to use collaborative technology, and we expected that these would have positive influences on perceived ease of use and perceived usefulness, and thus the first two hypotheses are as follows:

H1. Facilitating conditions are positively related to perceived ease of use.

H2. Facilitating conditions are positively related to perceived usefulness.

The TAM (Davis, 1989; Davis et al., 1989) is based on the idea that when users perceive that a technology is easy to use, they will more likely believe that it is useful for improving their job performance, and their attitudes will be more favorable towards the technology. In addition, when users perceive that a technology is useful, their attitudes towards the same will be more positive, and they will be more likely to accept and use it. Finally, if users' attitudes towards the technology are positive, then this will positively affect their intentions to use it (Chatzoglou et al., 2009; Huang et al., 2012). Consistent with these ideas, the third to seventh hypotheses are as follows:

H3. Perceived ease of use is positively related to perceived usefulness.

H4. Perceived ease of use is positively related to attitude towards using.

H5. Perceived usefulness is positively related to attitude towards using.

H6. Perceived usefulness is positively related to behavioural intention.

H7. Attitude towards using is positively related to behavioural intention.

Social influence is significant in shaping an individual's intention to use technology (Teo, 2009; Venkatesh \& Davis, 2000). Social influence is similar to the concept of the subjective norm (Venkatesh et al., 2003), which means that environmental factors, such as the opinions of friends, relatives, and other important people, have a significant effect on a person's behaviour (Lopez-Nicolas, Molina-Castillo, \& Bouwman, 2008). Research has shown that people seem to rely more on the opinions of others when they feel a greater degree of uncertainty with regard to the focal technology (Venkatesh \& Davis, 2000). In this study, social influence refers as the extent to which the students perceive that most people who are important to them believe that they should or should not use the collaborative technology. Based on this, the following hypothesis is proposed.

H8. Social influence is positively related to behavioural intention.

\section{Participants and grouping}

The participants were students from a university class in Tainan City, Taiwan. A total of 56 individuals enrolled in the experiment, in which the ILS was used to examine the learning styles of students. Of the students, 30 were categorised as sequential learners, and 26 as global learners, and the participants were divided into these groups based on their learning styles. The $t$-test results for the students' prior experience with computer usage showed that the mean and standard deviations were 8.90 and 2.93 in the sequential group, respectively, and 9.57 and 2.11 in the global group, and thus no significant difference existed between the groups ( $t=-0.97, p>0.05)$. The $t$-test results for the students' prior experience with Internet usage showed that the mean and standard deviation was 8.09 and 2.76 in the sequential group, respectively, and 8.73 and 2.18 in the global group, and thus no significant difference existed between the groups $(t=-0.94, p>0.05)$. Overall, the $t$-test results indicate that both groups had similar backgrounds with regard to computer and Internet usage.

\section{Measurement}

A structured questionnaire was developed based on a review of prior studies (Davis, 1989; Davis et al., 1989; Huang et al., 2012; Teo, 2009; Venkatesh \& Davis, 2000), as well as feedback from 10 participants and two experts. The questionnaire included the following six constructs: facilitating conditions, perceived ease of use, perceived usefulness, attitude towards using, social influence, and behavioural intention. Table 1 shows the final questionnaire that was distributed to the students, who were asked to indicate their level of agreement with the statements using a 5-point Likert scale. 
Table 1

The final questionnaire

\begin{tabular}{|c|c|}
\hline Construct & Item \\
\hline \multirow{4}{*}{$\begin{array}{l}\text { Facilitating } \\
\text { conditions }\end{array}$} & (FC1) I have the resources necessary to use the system. \\
\hline & (FC2) I have the knowledge necessary to use the system. \\
\hline & (FC3) The system is compatible with other systems I use. \\
\hline & (FC4) A specific person is available for assistance with system difficulties. \\
\hline \multirow{4}{*}{$\begin{array}{l}\text { Perceived } \\
\text { ease of use }\end{array}$} & (PEU1) I think that the functions of the system are clear and understandable. \\
\hline & (PEU2) It would be easy for me to become skillful at using the system. \\
\hline & (PEU3) I think that the system is easy to use. \\
\hline & (PEU4) Learning to operate the system is easy for me. \\
\hline \multirow{2}{*}{$\begin{array}{l}\text { Perceived } \\
\text { usefulness }\end{array}$} & (PU1) I think that the system is useful to assist me in creating slides. \\
\hline & $\begin{array}{l}\text { (PU2) I think that the system is useful to assist me in creating slides quickly. } \\
\text { (PU3) I think that the system can increase my efficiency in creating slides. } \\
\text { (PU4) If I use the system, I can create the better slides. }\end{array}$ \\
\hline Attitude & (ATU1) I think that using the system is a good idea. \\
\hline \multirow[t]{2}{*}{ towards using } & $\begin{array}{l}\text { (ATU2) I think that the system makes the creation of slides more interesting. } \\
\text { (ATU3) I think that using the system is fun. }\end{array}$ \\
\hline & (ATU4) I think that I like using the system to create slides. \\
\hline \multirow{3}{*}{$\begin{array}{l}\text { Social } \\
\text { influence }\end{array}$} & (SI1) People who influence my behaviour think that I should use the system. \\
\hline & (SI2) People who are important to me think that I should use the system. \\
\hline & $\begin{array}{l}\text { (SI3) My classmates who have good performance have benefited from using the system. } \\
\text { (SI4) In general, the teacher has supported the use of the system. }\end{array}$ \\
\hline \multirow{2}{*}{$\begin{array}{l}\text { Behavioural } \\
\text { intention }\end{array}$} & (BI1) I intend to use the system in the next $<\mathrm{n}>$ months. \\
\hline & $\begin{array}{l}\text { (BI2) I predict I would use the system in the next }<\text { n }>\text { months. } \\
\text { (BI3) I plan to use the system in the next }<\text { n }>\text { months. }\end{array}$ \\
\hline
\end{tabular}

\section{Tool of collaboration}

Prezi (http://prezi.com) is a cloud-based presentation service, in which users can create slides from their browsers, desktops, or mobile devices, so that they always have access to the latest versions of their work. Its main feature is to allow students directly to manage presentation slides, so that they can edit their files collaboratively on the Internet. Most importantly, compared to other collaborative tools, Prezi provides students with a setting that allows synchronous collaboration, and thus students can work together in real time, seeing immediately any changes that are made to the contents.

\section{Experimental procedure}

At the start of the experimental procedure the students took part in a learning activity, where they learned about the Internet. Once the learning activity was completed, the students were put randomly into several groups, each with three or four members, and were asked to create a survey about an innovative Internet application, and then to present the results of the survey, using Prezi to organise their work. The lecturer first demonstrated how to use Prezi to construct a synchronous collaborative context. During the slide creation activity, if the students had any questions they were answered by the lecturer. Finally, when the slide creation activity was completed, the participants were asked to complete the questionnaire that examined the proposed research model.

\section{Results and discussion}

The partial least squares approach was used to analyse the questionnaire data, as it is more suitable than structural equation modelling when handling small samples (minimum sample size $=20$ ) (Chin \& Newsted, 1999). The SmartPLS 2.0 software package was used to assess the measurements and structural models (Ringle, Wende, \& Will, 2005). Moreover, a boot-strapping resampling procedure was used to test the stability of the estimates, in which Chin (1998) recommends resampling 500 times. 


\section{Measurement model}

The measurement model was assessed with regard to item loadings, convergent validity, reliability of measures, and discriminant validity. An item was considered to be reliable if its loading was greater than 0.70 (Chin \& Newsted, 1999). The convergent validity was assessed using the average variance extracted, which must exceed a standard minimum level of 0.5 (Hair, Black, Babin, Anderson, \& Tatham, 2006). The reliability of the measures was examined through the use of composite reliability and Cronbach's alpha. In general, the minimum value of composite reliability is 0.7 , and the minimum value of Cronbach's alpha is 0.6 (Hair et al., 2006). The discriminant validity was assessed by using the square root of the average variance extracted and latent variable correlations. The square root of the average variance extracted of each construct should exceed the correlation shared between one construct and the other constructs in the model (Fornell \& Larcker, 1981). Tables 1, 2, and 3 show the results of the measurement model were acceptable, since all the values met the standard levels.

Table 2

The item loadings for the measurement model

\begin{tabular}{lccccc}
\hline Construct & Items & Loading & $\begin{array}{c}\text { Standard } \\
\text { deviation }\end{array}$ & Standard error & T-value \\
\hline Facilitating & (FC1) & 0.94 & 0.01 & 0.01 & 80.70 \\
conditions & (FC2) & 0.93 & 0.01 & 0.01 & 49.18 \\
& (FC3) & 0.92 & 0.01 & 0.01 & 58.45 \\
Perceived ease & (FC4) & 0.84 & 0.03 & 0.03 & 23.68 \\
of use & (PEU1) & 0.83 & 0.03 & 0.03 & 21.27 \\
& (PEU2) & 0.91 & 0.01 & 0.01 & 53.91 \\
Perceived & (PEU3) & 0.94 & 0.01 & 0.01 & 70.99 \\
usefulness & (PEU4) & 0.95 & 0.01 & 0.01 & 86.13 \\
& (PU1) & 0.88 & 0.03 & 0.03 & 28.20 \\
Attitude & (PU2) & 0.94 & 0.01 & 0.01 & 78.62 \\
towards using & (PU3) & 0.95 & 0.01 & 0.01 & 83.96 \\
& (PU4) & 0.90 & 0.01 & 0.01 & 53.42 \\
Social influence & (ATU1) & 0.91 & 0.02 & 0.02 & 44.29 \\
& (ATU2) & 0.89 & 0.04 & 0.04 & 19.31 \\
& (ATU3) & 0.95 & 0.00 & 0.00 & 109.42 \\
& (ATU4) & 0.93 & 0.01 & 0.01 & 71.42 \\
Behavioural & (SI) & 0.93 & 0.01 & 0.01 & 64.87 \\
intention & (SI3) & 0.90 & 0.01 & 0.01 & 45.22 \\
& (SI4) & 0.88 & 0.02 & 0.02 & 32.50 \\
\hline & (BI1) & 0.91 & 0.06 & 0.06 & 11.50 \\
& (BI2) & 0.93 & 0.01 & 0.01 & 57.71 \\
& (BI3) & 0.96 & 0.02 & 0.02 & 46.59 \\
& & 0.00 & 0.00 & 125.91 \\
\hline
\end{tabular}

Table 3

The convergent validity and reliability of the measures in the measurement model

\begin{tabular}{lccc}
\hline \multirow{2}{*}{ Construct } & Convergent validity & \multicolumn{2}{c}{ Reliability } \\
\cline { 2 - 4 } & AVE & Composite reliability & Cronbach’s alpha \\
\hline Facilitating conditions & 0.83 & 0.95 & 0.93 \\
Perceived ease of use & 0.83 & 0.95 & 0.93 \\
Perceived usefulness & 0.85 & 0.95 & 0.94 \\
Attitude towards using & 0.86 & 0.96 & 0.94 \\
Social influence & 0.74 & 0.92 & 0.88 \\
Behavioural intention & 0.90 & 0.96 & 0.94 \\
\hline
\end{tabular}


Table 4

The discriminant validity of the measurement model

\begin{tabular}{|c|c|c|c|c|c|c|}
\hline \multirow[b]{3}{*}{ Construct } & \multicolumn{6}{|c|}{ Discriminant validity } \\
\hline & \multicolumn{6}{|c|}{ Latent variable correlations } \\
\hline & $\begin{array}{l}\text { Facilitating } \\
\text { conditions }\end{array}$ & $\begin{array}{l}\text { Perceived } \\
\text { ease of use }\end{array}$ & $\begin{array}{l}\text { Perceived } \\
\text { usefulness }\end{array}$ & $\begin{array}{l}\text { Attitude } \\
\text { towards using }\end{array}$ & $\begin{array}{l}\text { Social } \\
\text { influence }\end{array}$ & $\begin{array}{l}\text { Behavioural } \\
\text { intention }\end{array}$ \\
\hline $\begin{array}{l}\text { Facilitating } \\
\text { conditions }\end{array}$ & 0.91 & & & & & \\
\hline $\begin{array}{l}\text { Perceived } \\
\text { ease of use }\end{array}$ & 0.81 & 0.91 & & & & \\
\hline $\begin{array}{l}\text { Perceived } \\
\text { usefulness }\end{array}$ & 0.76 & 0.69 & 0.92 & & & \\
\hline $\begin{array}{l}\text { Attitude } \\
\text { towards using }\end{array}$ & 0.81 & 0.75 & 0.83 & 0.92 & & \\
\hline $\begin{array}{l}\text { Social } \\
\text { influence }\end{array}$ & 0.77 & 0.66 & 0.75 & 0.74 & 0.86 & \\
\hline $\begin{array}{l}\text { Behavioural } \\
\text { intention }\end{array}$ & 0.72 & 0.61 & 0.68 & 0.81 & 0.77 & 0.94 \\
\hline
\end{tabular}

\section{Structural model}

A structural model was used to verify the hypotheses based on the path coefficients and $R^{2}$ values (Chin \& Newsted, 1999). The $R^{2}$ values were used to assess the ability of the model to explain the variance in the dependent variables. The path coefficients were used to assess the statistical significance of the hypotheses. Figure 2 shows the results of the structural model, and it can be seen that the model explains $60 \%$ of the variation in perceived ease of use, $65 \%$ of the variation in perceived usefulness, $75 \%$ of the variation in attitude towards using, and $72 \%$ of the variation in behavioural intention.

Eight path coefficients are also given in Figure 2. First, the path coefficient between facilitating conditions and perceived ease of use was $0.81, p<0.05$, which indicates that facilitating conditions had a positive and significant influence on perceived ease of use. Second, the path coefficient between facilitating conditions and perceived usefulness was $0.59, p<0.05$, which indicates that facilitating conditions had a positive and significant influence on perceived usefulness. Third, the path coefficient between perceived ease of use and perceived usefulness was $0.21, p>0.05$, which indicates that perceived ease of use did not have a positive and significant influence on perceived usefulness. Fourth, the path coefficient between perceived ease of use and attitude towards using was $0.33, p<0.05$, which indicates that perceived ease of use had a positive and significant influence on attitude towards using. Fifth, the path coefficient between perceived usefulness and attitude towards using was $0.59, p<0.05$, which indicates that perceived usefulness had a positive and significant influence on attitude towards using. Sixth, the path coefficient between perceived usefulness and behavioural intention was $-0.16, p>$ 0.05, which indicates that perceived usefulness did not have a positive and significant influence on behavioural intention. Seventh, the path coefficient between attitude towards using and behavioural intention was 0.62, $p<0.05$, which indicates that attitude towards using had a positive and significant influence on behavioural intention. Eighth, the path coefficient between social influence and behavioural intention was $0.43, p<0.05$, which indicates that social influence had a positive and significant influence on behavioural intention. These results indicate that two hypotheses were rejected, namely $\mathrm{H} 3$ and H6, while H1, H2, H4, H5, H7, and H8 were accepted. 


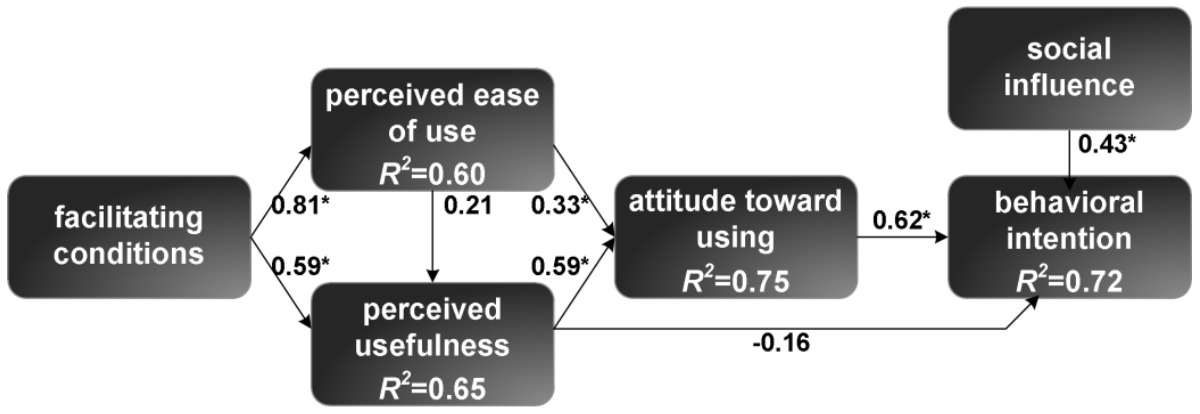

Note: Marked coefficients $\left(^{*}\right)$ are significant at $p<0.05(T>1.96)$.

Figure 2. The results of the structural model

To further explore the factors that affect students' intention to use a collaborative technology, the direct, indirect, and total effects of each construct on behavioural intention are summarised in Table 5. According to Cohen (1988), effect sizes with values less than 0.1 are considered small, those between 0.1 and 0.3 are medium, and values of 0.5 or more are large. Table 5 shows that all the constructs in the research model had a significant effect on the behavioural intention of the subjects to use the collaborative technology. Among these constructs, only attitude towards using has a large effect size, whereas the other constructs have small or medium effects on the intention to use the technology. Therefore, the dominant determinant of behavioural intention is attitude towards using, with a total effect of 0.62 . This is followed by social influence, facilitating conditions, perceived usefulness, and perceived ease of use, with total effects of $0.43,0.39,0.37$, and 0.21 , respectively. That is to say, the answer to the first research question is that the students' views of the collaborative technology were mainly influenced by attitude towards using, followed by social influence and facilitating conditions.

Table 5

The direct, indirect and total effects on intention to use the collaborative technology

\begin{tabular}{lcccc}
\hline Dependent variable & Independent variables & Direct effects & Indirect effects & Total effects \\
\hline & Facilitating conditions & - & 0.39 & 0.39 \\
& Perceived ease of use & - & 0.21 & 0.21 \\
Behavioural intention & Perceived usefulness & non-significant & 0.37 & 0.37 \\
& Attitude towards using & 0.62 & - & 0.62 \\
& Social influence & 0.43 & - & 0.43 \\
\hline
\end{tabular}

\section{Analysis of the perspectives of sequential and global students}

Further analysis was carried out to investigate whether the views of the sequential students with regard to the collaborative technology were similar to those of the global students. First of all, structural models for the sequential and global students were developed to investigate this, as shown in Figure 3 and Figure 4. The direct, indirect, and total effects of each construct on behavioural intention for the sequential and global students are summarised in Table 6 and Table 7, based on the related structural models.

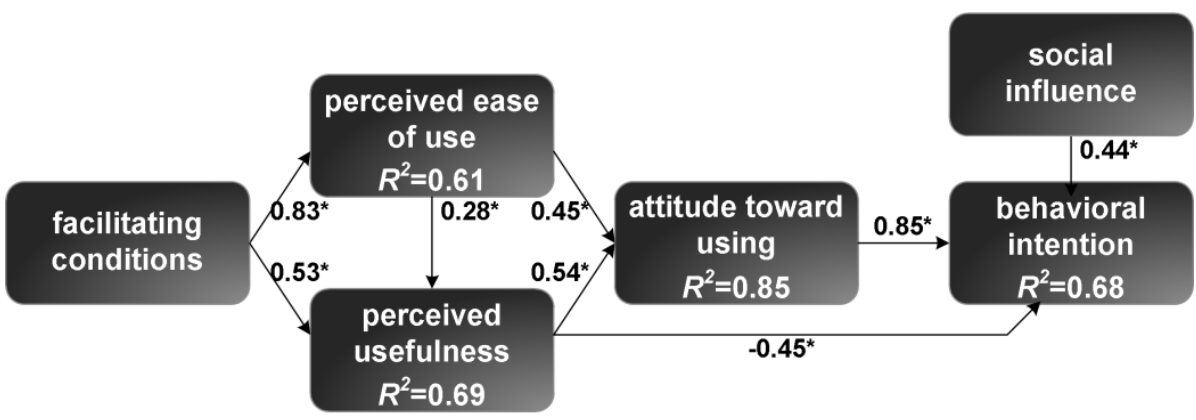

Note: Marked coefficients $\left(^{*}\right)$ are significant at $p<0.05(T>1.96)$.

Figure 3. The structural model for the sequential students 


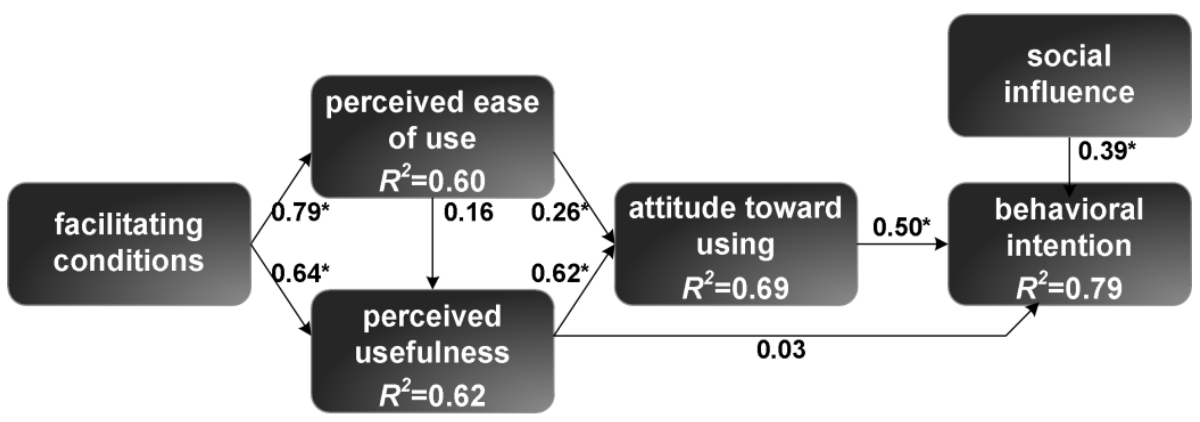

Note: Marked coefficients $\left(^{*}\right)$ are significant at $p<0.05(T>1.96)$.

Figure 4. The structural model for the global students

Table 6

The direct, indirect and total effects on behavioural intention for the sequential students

\begin{tabular}{lcccc}
\hline Dependent variable & Independent variables & Direct effects & Indirect effects & Total effects \\
\hline \multirow{5}{*}{ Behavioural intention } & Facilitating conditions & - & 0.30 & 0.30 \\
& Perceived ease of use & - & 0.13 & 0.13 \\
& Perceived usefulness & non-significant & 0.31 & 0.31 \\
& Attitude towards using & 0.50 & - & 0.50 \\
& Social influence & 0.39 & - & 0.39 \\
\hline
\end{tabular}

Table 7

The direct, indirect and total effects on behavioural intention for the global students

\begin{tabular}{lcccc}
\hline Dependent variable & Independent variables & Direct effects & Indirect effects & Total effects \\
\hline & Facilitating conditions & - & 0.32 & 0.32 \\
& Perceived ease of use & - & 0.38 & 0.38 \\
Behavioural intention & Perceived usefulness & -0.45 & 0.46 & 0.01 \\
& Attitude towards using & 0.85 & - & 0.85 \\
& Social influence & 0.44 & - & 0.44 \\
\hline
\end{tabular}

Two points should be observed in the tables above. The first is that the sequential students' views of the collaborative technologies were mainly influenced by attitude towards using, followed by social influence and facilitating conditions, similar to the findings for the global students. Thus, it can be concluded that attitude towards using, social influence and facilitating conditions are the three most important determinants of students' intention to use a collaborative technology, regardless of their learning styles.

The second point is that the effects of perceived ease of use and perceived usefulness on behavioural intention were clearly different between the sequential and global students. For the sequential students, perceived ease of use had a small impact on behavioural intention (total effects $=0.13$ ), while perceived usefulness had a large impact (total effects $=0.31$ ). Conversely, for the global students, perceived ease of use had a large impact on behavioural intention (total effects $=0.38$ ), while perceived usefulness had a small impact (total effects $=0.03$ ). Therefore, it can be concluded that perceived usefulness significantly influenced the sequential students' intention to use the collaborative technology, while perceived ease of use significantly influenced the global students' intention to use it. Consequently, the answer to the second research question is that the sequential students were more concerned about whether the system could assist them in undertaking collaborative work, while the global students were more concerned about whether the system was easy to use.

\section{Discussion}

The results shown in Table 5 indicate that attitude towards using had the most significant and positive effect on behavioural intention, followed by social influence and facilitating conditions. This suggests that when any of these three factors are present, students are more likely to use a collaborative technology. Since any one of these individually will increase the likelihood of students using such technologies, it is 
reasonable to assume that if two or more are present simultaneously, the students' motivation to use the technology will be increased even further. These results echo the findings of previous studies. First, the results support existing research that posits a close relationship between attitude towards using and behavioural intention. Luan, Fung, Nawawi, and Hong (2005) showed that when users have more positive attitudes towards Internet use, then they spend longer online than others with less positive attitudes. Similarly, Teo (2012) also found that attitude towards using has a significant influence on behavioural intention. This means that the effective implementation of a technology depends on users having a positive attitude towards using it, no matter how sophisticated and powerful it is (Huang \& Liaw, 2005). Next, the results support existing research that posits a close relationship between social influence and behavioural intention. Gruzd, Staves, and Wilk (2012) found that social influence has a positive effect on users' intention to use social media. Similarly, Cheung and Vogel (2013) as well as McKenna, Tuunanen, and Gardner (2013) also found that the use of collaborative technologies is affected by social influence. Such technologies provide users with a context in which they can interact and work with others. During the period of co-creation, group members may feel obligated to use the technology, because they have a shared goal. Accordingly, the sense of belonging to a group will be formed and will further encourage people to use the technology. Finally, the results of this work support existing research that posits a close relationship between facilitating conditions and behavioural intention. One reason for this may be that, for the students examined in this work, collaborative technologies are still relatively new, and thus the majority had little experience of using them for learning. Therefore, the facilitating conditions, such as instructions on how to use the collaborative technology, had a significant effect on the students' intention to use it. Karaali et al. (2011) found that helpful support can encourage employees to use web-based learning systems. Similarly, Escobar-Rodriguez and Monge-Lozano (2012) showed that training in how to use a new technology can enhance students' productivity, as they do not need to waste much time learning how to do so on their own.

The results shown in Table 6 and Table 7 reveal that the sequential students were concerned about whether the technology was useful in their collaborations, while the global students were more concerned about whether it was easy to use. One possible reason for these results is that the sequential students had a low level of motivation to explore how to use the technology to achieve collaboration, and consequently they wanted the technology to provide them with more useful functions to achieve this. In contrast, the global students had a stronger motivation to explore how to use the technology to achieve collaboration, and consequently wanted it to be easier to use, so that they could make use of more of its functions. This echoes the findings of Filippidis and Tsoukalas (2009), whose results show that students who are sequential learners are also likely to have a sensory way of learning, whereas students who are global are more likely to have an intuitive one. Clearly, the sequential students wanted the technology to be useful, while the global students wanted it to be easy to use. Similarly, Filippidis and Tsoukalas (2009) and Graf et al. (2009) stated that sequential students prefer linear thinking processes and learning in small, incremental steps, while global students prefer holistic thinking processes and learning in large leaps. That is to say, a useful technology can assist sequential students in learning step by step, while an easy-touse technology can assist global students in learning by trial and error. In addition, the sequential-global dimension can correspond to Witkin's (1949) field dependence-independence dimension (Van Zwanenberg, Wilkinson, \& Anderson, 2000). Studies show that field dependent learners are sensitive to social interactions and tend to be more passive learners who prefer external information structures, while field independent learners are more individualistic and self-structuring (Angeli, 2013; Garger \& Guild, 1984; Saracho, 1989). The sequential students in the current work can thus be seen as field dependent learners, and so prefer to accomplish a task collaboratively, while the global students can be seen as field independent learners, and thus prefer to accomplish a task individually. This may mean that sequential students benefit more from collaborative technologies than global students, because the former focus their attention on the usefulness of such technologies and use them to improve their learning performance.

\section{Conclusions}

The goal of this research, which is based on the TAM, was to add new variables, namely facilitating conditions and social influence, to the research model, and to explore the factors that affect the intentions of sequential and global learners to use a collaborative technology. An empirical study was conducted to test and validate the research model and to investigate the impacts of specific variables. The empirical results show that attitude towards using is the most important determinant of students' intention to use a collaborative technology, followed by social influence and facilitating conditions. In addition, the 
sequential students were more concerned about the perceived usefulness of the collaborative technology, while the global students were more concerned about the perceived ease of use. Accordingly, the results provide valuable insights that may help practitioners and researchers to better understand how students' experiences and perceptions impact their intention to use collaborative technologies, which is arguably an effective overall indicator to assess the success of applying such technologies in a learning context. This better understanding, obtained from a multidimensional perspective, can offer a more holistic view of how to improve the development and use of collaborative technologies.

The results of this study have two practical implications drawn for teachers and instructional software designers. First, attitude towards using, social influence, and facilitating conditions were found to be useful in promoting students' intention to use the collaborative technology. This implies that when teachers want to apply such technologies in their work, they should first attempt to persuade students that using collaborative technologies will lead to positive feelings, and that people who are important to them, such as their classmates, think that they should use the technology. Teachers should also offer guidance and support, as this will also make students more likely to use a collaborative technology. Second, the results indicate that sequential students are most concerned about the perceived usefulness of such technologies, while global students care more about the perceived ease of use. This implies that sequential students and global students have different requirements for instructional software, especially with regard to usefulness and ease of use. Accordingly, instructional software designers may attempt to design collaborative technologies based on the types of students that will use them, so that users can learn more efficiently and effectively.

While this study revealed some findings, some limitations remain and should be considered in future work. First, the data used in this study are limited to the students' self-reported perceptions. In future work, some additional measurements could be used to collect the perspectives of students on collaborative technologies. Second, in this study we did not analyse the demographic data of the samples, because they were from the same university department; that is to say, the samples used in this study are taken from a relatively homogeneous group. In future work, students from different departments should be chosen as the sample candidates, so that we can use their demographic data, including gender, age, and educational background, to investigate whether demographics influence the perspectives of students on such technologies. Furthermore, the sample size should be increased to strengthen the validity of the findings in any future work.

\section{Acknowledgements}

The authors would like to thank the Ministry of Science and Technology of the Republic of China for financially supporting this research under Contract No. MOST 102-2511-S-041-001- and 102-2511-S041-005-.

\section{References}

Angeli, C. (2013). Examining the effects of field dependence-independence on learners' problem-solving performance and interaction with a computer modeling tool: Implications for the design of joint cognitive systems. Computers \& Education, 62, 221-230. doi:10.1016/j.compedu.2012.11.002

Chatzoglou, P. D., Sarigiannidis, L., Vraimaki, E., \& Diamantidis, A. (2009). Investigating Greek employees' intention to use web-based training. Computers \& Education, 53(3), 877-889. doi:10.1016/j.compedu.2009.05.007

Cheung, R., \& Vogel, D. (2013). Predicting user acceptance of collaborative technologies: An extension of the technology acceptance model for e-learning. Computers \& Education, 53, 160-175. doi:10.1016/j.compedu.2012.12.003

Chin, W. W., \& Newsted, P. R. (1999) Structural equation modeling analysis with small samples using partial least squares. In R. Hoyle (Ed.), Statistical strategies for small sample research (pp. 307-341). Thousand Oaks, CA: Sage Publications.

Chin, W.W. (1998). The partial least squares approach to structural equation modeling. In G. A. Marcoulides (Ed.), Modern methods for business research (pp. 295-336). New Jersey: Lawrence Erlbaum Associates.

Cohen, J. (1988). Statistical power analysis for the behavioral sciences (2nd ed.). Hillsdale, NJ: Erlbaum. 
Chiu, C. H., Huang, C. C., \& Chang, W. T. (2000). The evaluation and influence of interaction in network supported collaborative concept mapping. Computers \& Education, 34(1), 17-25. doi:10.1016/S03601315(99)00025-1

Coll, C., Rochera, M. J., \& Gispert, I. D. (2014). Supporting online collaborative learning in small groups: Teacher feedback on learning content, academic task and social participation. Computers \& Education, 75, 53-64. doi:10.1016/j.compedu.2014.01.015

Davis, F. D. (1989). Perceived usefulness, perceived ease of use and user acceptance of information technology. MIS Quarterly, 13(3), 319-340. doi:10.2307/249008

Davis, F. D., Bagozzi, R. P., \& Warshaw, P. R. (1989). User acceptance of computer technology: A comparison of two theoretical models. Management Science, 35(8), 982-1003. doi:10.1287/mnsc.35.8.982

Escobar-Rodriguez, T., \& Monge-Lozano, P. (2012). The acceptance of Moodle technology by business administration students. Computers \& Education, 58(4), 1085-1093. doi:10.1016/j.compedu.2011.11.012

Felder, R. M., \& Silverman, L. K. (1988). Learning and teaching styles in engineering education. Engineering Education, 78(7), 674-681.

Felder, R. M., \& Soloman, B. A. (1997). Index of learning styles questionnaire. Raleigh: North Carolina State University. Retrieved from http://www.engr.ncsu.edu/learningstyles/ilsweb.html

Filippidis, S. K., \& Tsoukalas, I. A. (2009). On the use of adaptive instructional images based on the sequential-global dimension of the Felder-Silverman learning style theory. Interactive Learning Environments, 17(2), 135-150. doi:10.1080/10494820701869524

Fishbein, M., \& Azjen, I. (1975). Belief, attitude, intention and behavior: An introduction to theory and research. Reading, MA: Addison-Wesley.

Fornell, C., \& Larcker, D. F. (1981). Evaluating structural equation models with unobservable variables and measurement error. Journal of Marketing Research, 18(1), 39-50. doi:10.2307/3151312

Garger, S., \& Guild, P. (1984). Learning styles: The crucial differences. Curriculum Review, 23(1), 9-12. Retrieved from ERIC database. (EJ297006)

Geary, D. C. (1995). Reflections of evolution and culture in children's cognition: Implications for mathematical development and instruction. American Psychologist, 50, 24-37. Retrieved from http://www.apa.org/pubs/journals/amp/

Graf, S., Kinshuk, \& Liu, T. C. (2009). Supporting teachers in identifying students' learning styles in learning management systems: an automatic student modelling approach. Educational Technology \& Society, 12(4), 3-14. Retrieved from http://www.ifets.info/

Gruzd, A., Staves, K., \& Wilk, A. (2012). Connected scholars: Examining the role of social media in research practices of faculty using the UTAUT model. Computers in Human Behavior, 28(6), 23402350. doi:10.1016/j.chb.2012.07.004

Hair, J. F., Black, W. C., Babin, B. J., Anderson, R. E., \& Tatham, R. L. (2006). Multivariate data analysis (6th ed.). Upper Saddle River, NJ: Prentice-Hall.

Harel, I., \& Papert, S. (Eds.). (1991). Constructionism. Norwood, NJ: Ablex Publishing.

Huang, E. Y., Lin, S. W., \& Huang, T. K. (2012). What type of learning style leads to online participation in the mixed-mode e-learning environment? A study of software usage instruction. Computers \& Education, 58(1), 338-349. doi:10.1016/j.compedu.2011.08.003

Huang, H.M., \& Liaw, S.S. (2005). Exploring user's attitudes and intentions toward the web as a survey tool. Computers in Human Behavior, 21(5), 729-743. doi:10.1016/j.chb.2004.02.020

Huang, Y. M., Huang, Y. M., Huang, S. H., \& Lin, Y. T. (2012). A ubiquitous English vocabulary learning system: Evidence of active/passive attitudes vs. usefulness/ease-of-use. Computers \& Education, 58(1), 273-282. doi:10.1016/j.compedu.2011.08.008

Huang, Y. M., Wang, C. S., Guo, J. Z., Shih, H. Y., \& Chen, Y. S. (2013). Advancing collaborative learning with cloud service. Lecture Notes in Electrical Engineering, 253, 717-722. doi:10.1007/97894-007-6996-0_75

Hwang, G. J., Sung, H. Y., Hung, C. M., \& Huang, I. (2013). A learning style perspective to investigate the necessity of developing adaptive learning systems. Educational Technology \& Society, 16(2), 188197. Retrieved from http://www.ifets.info/

Hwang, G. J., Sung, H. Y., Hung, C. M., Huang, I., \& Tsai, C. C. (2012). Development of a personalized educational computer game based on students' learning styles. Educational Technology Research and Development, 60(4), 623-638. doi:10.1007/s11423-012-9241-x

Jeffrey, L. M. (2009). Learning orientations: Diversity in higher education. Learning and Individual Differences, 19(2), 195-208. doi:10.1016/j.lindif.2008.09.004 
Karaali, D., Gumussoy, C. A., \& Calisir, F. (2011). Factors affecting the intention to use a web-based learning system among blue-collar workers in the automotive industry. Computers in Human Behavior, 27(1), 343-354. doi:10.1016/j.chb.2010.08.012

Keefe, J. W. (1979). Learning style: An overview. In NASSPS Student learning styles: Diagnosing and prescribing programs (pp. 1-17). Reston, VA: National Association of Secondary School Principals.

Kolb, D. A. (1984). Experiential learning: Experience as the source of learning and development. Englewood Cliffs, NJ: Prentice-Hall.

Lee, W. B., Cheung, C. F., Tsui, E., \& Kwok, S. K. (2007). Collaborative environment and technologies for building knowledge work teams in network enterprises. International Journal of Information Technology and Management, 6(1), 5-22. doi:10.1504/IJITM.2007.011904

Liaw, S. S., Chen, G. D., \& Huang, H. M. (2008). Users’ attitudes toward Web-based collaborative learning systems for knowledge management. Computers \& Education, 50(3), 950-961. doi:10.1016/j.compedu.2006.09.007

Lopez-Nicolas, C., Molina-Castillo, F. J., \& Bouwman, H. (2008). An assessment of advanced mobile services acceptance: Contributions from TAM and diffusion theory models. Information \& Management, 45(6), 359-364. doi:10.1016/j.im.2008.05.001

Lu, J., Liu, C., Yu, C. S., \& Wang, K. (2008). Determinants of accepting wireless mobile data services in China. Information \& Management, 45(1), 52-64. doi:10.1016/j.im.2007.11.002

Luan, W.S., Fung, N.S., Nawawi, M., \& Hong, T.S. (2005). Experienced and inexperienced Internet users among pre-service teachers: Their use and attitudes toward the Internet. Educational Technology \& Society, 8(1), 90-103. Retrieved from http://www.ifets.info/

McCarthy, C., Bligh, J., Jennings, K., \& Tangney, B. (2005). Virtual collaborative learning environments for music: Networked drumsteps. Computers \& Education, 44(2), 173-195. doi:10.1016/j.compedu.2004.08.004

McKenna, B., Tuunanen, T., \& Gardner, L. (2013). Consumers’ adoption of information services. Information \& Management, 50(5), 248-257. doi:10.1016/j.im.2013.04.004

Palincsar, A. S. (1998). Social constructivist perspectives on teaching and learning. Annual Review of Psychology, 49, 345-375. doi:10.1146/annurev.psych.49.1.345

Park, H., \& Seo, S. (2013). Effects of collaborative activities on group identity in virtual world. Interactive Learning Environments, 21(6), 516-527. doi:10.1080/10494820.2011.604037

Ringle, C. M., Wende, S., \& Will, A. (2005). SmartPLS 2.0 (beta). Retrieved from http://www.smartpls.de

Rouibah, K., Hamdy, H. I., \& Al-Enezi, M. Z. (2009). Effect of management support, training, and user involvement on system usage and satisfaction in Kuwait. Industrial Management \& Data Systems, 109(3), 338-356. doi:10.1108/02635570910939371

Saracho, O. N. (1989). Cognitive style: individual differences. Early Child Development and Care, 53, 75-81. Retrieved from http://www.tandfonline.com/toc/gecd20/current\#.VIQUImSUfiI

Schunk, D. H. (1996). Learning theories. Upper Saddle River, NJ: Prentice-Hall.

Sung, H. Y., \& Hwang, G. J. (2013). A collaborative game-based learning approach to improving students' learning performance in science courses. Computers \& Education, 63, 43-51. doi:10.1016/j.compedu.2012.11.019

Teo, T. (2009). Modelling technology acceptance in education: A study of pre-service teachers. Computers \& Education, 52(1), 302-312. doi:10.1016/j.compedu.2008.08.006

Teo, T. (2012). Examining the intention to use technology among pre-service teachers: An integration of the technology acceptance model and theory of planned behavior. Interactive Learning Environments, 20(1), 3-18. doi:10.1080/10494821003714632

Terzis, V., \& Economides, A. A. (2011). Computer based assessment: Gender differences in perceptions and acceptance. Computers in Human Behavior, 27(6), 2108-2122. doi:10.1016/j.chb.2011.06.005

Van Zwanenberg, N., Wilkinson, L. J., \& Anderson, A. (2000). Felder and Silverman's index of learning styles and Honey and Mumford's learning styles questionnaire: How do they compare and do they predict academic performance? Educational Psychology, 20(3), 365-380. doi:10.1080/713663743

Venkatesh, V., \& Davis, F.D. (2000). A theoretical extension of the technology acceptance model: Four longitudinal field studies. Management Science, 46(2), 186-204. doi:10.1287/mnsc.46.2.186.11926

Venkatesh, V., Morris, M. G., Davis, G. B., \& Davis, F. D. (2003). User acceptance of information technology: toward a unified view. MIS Quarterly, 27(3), 425-478. Retrieved from http://www.misq.org/

Wang, Q. (2009). Design and evaluation of a collaborative learning environment. Computers \& Education, 53(4), 1138-1146. doi:10.1016/j.compedu.2009.05.023

Wang, Q. (2010). Using online shared workspaces to support group collaborative learning. Computers \& 
Education, 55(3), 1270-1276. doi:10.1016/j.compedu.2010.05.023

Witkin, H. A. (1949). The nature and importance of individual differences in perception. Journal of Personality, 18(2), 145-170. doi:10.1111/j.1467-6494.1949.tb01237.x

Corresponding author: Yong-Ming Huang, ym.huang.tw@gmail.com

Australasian Journal of Educational Technology @ 2015.

Please cite as: Huang, Y-M. (2015). Exploring the factors that affect the intention to use collaborative technologies: The differing perspectives of sequential/global learners. Australasian Journal of Educational Technology, 31(3), 278-292. 